\title{
Adsorptive Removal of Arsenic from Aqueous Solutions Using Amino Functionalized Super paramagnetic Iron Oxide Nanoparticle/SiO
}

\author{
Hadi Noorizadeh (D) a Abbas Farmany (iD b,*
}

\section{AR T I C L E I N F O}

Received: 17 December 2018

Revised: 28 December 2018

Accepted: 24 January 2019

Available online: 2 February 2019

\section{K E Y W O R D S}

As (III)

Super paramagnetic iron oxide

nanoparticle $/ \mathrm{SiO}_{2}-\mathrm{NH}_{2}$

Adsorption

\section{A B S T R A C T}

The adsorption features of amino functionalized super paramagnetic iron oxide nanoparticle $/ \mathrm{SiO}_{2}$ for selective removal of arsenic in water is evaluated. Amino functionalized super paramagnetic Iron Oxide nanoparticle $/ \mathrm{SiO}_{2}$ is synthesized and characterized with Fourier transform infrared spectroscopy (FTIR), $\mathrm{X}$-ray diffraction (XRD), and electron microscope (SEM). FTIR shows amine group successfully attached to nanoparticle. XRD-diffraction pattern shows that the magnetic phase of super paramagnetic nanoparticle is magnetized by inverse spinel crystal structure. SEM image was used to study the morphology of super paramagnetic nanoparticle. The adsorption capability of the nanoparticle was examined in batch system. The nanoparticle was applied to removal of arsenic from aqueous media. It was shown that the adsorption of arsenic on the nanoparticle was depended on PH and contact time.

G R A P H I C A L A B S T R A C T

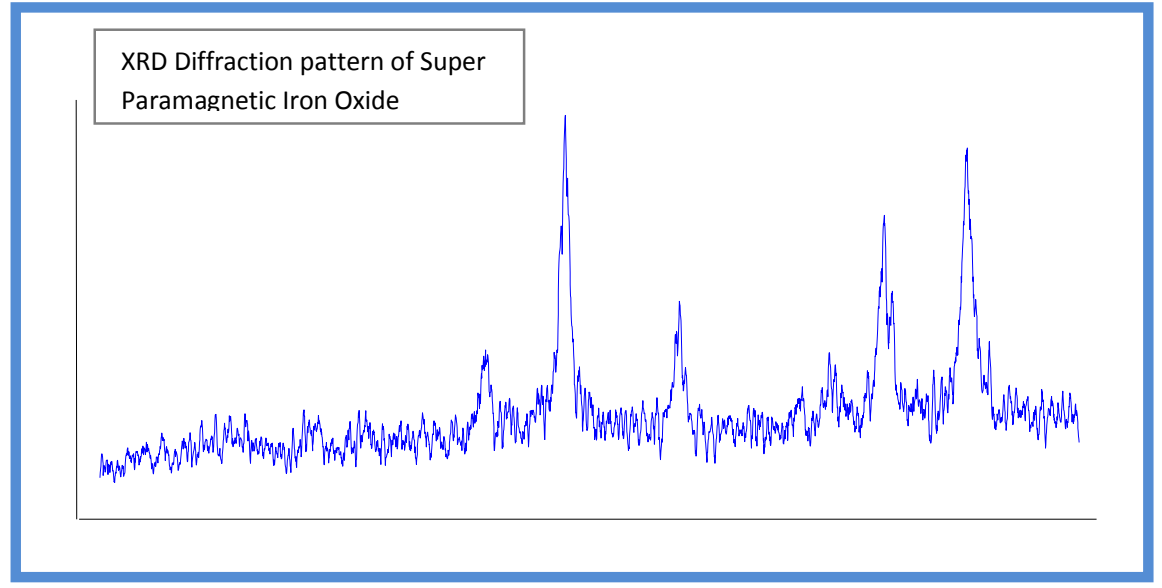

\footnotetext{
* Corresponding author's E-mail address: abbasfarmany@yahoo.com, Tel.: +98838394677

a Yaoung Researchers \& Elite Club, Ilam Branch, Islamic Azad University, Ilam, Iran.

b Dental Research Center, Hamadan University of Medical Science, Hamadan, Iran.
} 


\section{Introduction}

Arsenic is a highly toxic metalloid to humans, animals and plants. High amounts of arsenic in the human body cause skin cancer, lung and bladder. Arsenic toxicity depends on the type of compounds. Most important forms of arsenic in natural surface water are the samples of inorganic arsenite $\mathrm{HAsO}_{3}{ }^{2-}$, $\mathrm{HAsO}$ and $\mathrm{H}_{2} \mathrm{AsO}_{4}[1,2]$.

Recent report of WHO argue that some million people in United States have been exposed to arsenic contaminated water (An, Liang and Zhao 2011.)[3]. As per guide lines of USEPA, maximum toxic level of arsenic in drinking water is $0.01 \mathrm{mg} / \mathrm{L}$ [4]. So, it is of interest to develop new methods for arsenic removal from water. At this time, a lot of methods are employed to remove the arsenic from water including the aeration/ coagulation, adsorption on iron and aluminum, ion exchange, precipitation, electrode analysis and reverse osmosis etc. When in some of these methods a large amount of material used, the volume of sludge production is high.

At this time, various naturally available adsorbents such as cake, pine needles, wool, olive sawdust etc. were used for the removal of arsenic [5, 6]. However, many of these naturally available adsorbents have low arsenic adsorption capacity and slow process kinetics. Thus, there is a need to develop innovative adsorbents for removal of toxic metals.

Iron oxide nanoparticles have shown prominent result for removal of arsenic from water [7-9]. These nanoparticles could become cost-effective nanomaterials for decontamination of arsenic. It was believed that the use of amine group in the surface of iron nanoparticle exhibited a high potential for the adsorption of organic/inorganic materials [10-14]. Also, $\mathrm{Fe}_{3} \mathrm{O}_{4}$-graphene composite showed high arsenic removal due to free sites in the surface of nanoparticle enhanced adsorption of arsenic [12]. The advantages of superparamagnetic Iron Oxide nanoparticles such as efficient removal and easy separation motivated us to consider this nanomaterial as adsorbent for removal of arsenic. In this paper, amino functionalized super paramagnetic iron oxide nanoparticles $/ \mathrm{SiO}_{2}$ core/shell nanoparticle was synthesized and used for adsorptive removal of As (III) ion from aqueous solutions.

\section{Experimental}

\section{Material and methods}

All chemicals were of analytical grade and used as received. Ferrous chloride tetra hydrate $\left(\mathrm{FeCl}_{2} \cdot 4 \mathrm{H}_{2} \mathrm{O}>99 \%\right)$ ferric chloride hex hydrate $\left(\mathrm{FeCl}_{3} \cdot 6 \mathrm{H}_{2} \mathrm{O}>99 \%\right)$, sodium hydroxide ( $\geq 97 \%$ ), and hydrochloric acid (37\%), were purchased from Merck 
(Germany).

(3-aminopropyl)-

triethoxysilane (APTES, 99\%) was purchased from Aldrich (Germany). All aqueous solutions were prepared with double distilled water. The FT-IR spectra were recorded by an Infrared spectrophotometer coupled to Fourier transform (FTIR, Perkin Elmer1600, and USA).

\section{Synthesis of Super paramagnetic Nanoparticles}

Super paramagnetic iron oxide nanoparticles were prepared via an improved chemical co-precipitation method [13]. Briefly, $\mathrm{FeCl}_{2} \cdot 4 \mathrm{H}_{2} \mathrm{O}(1.5 \mathrm{mmol})$ and $\mathrm{FeCl}_{3} \cdot 6 \mathrm{H}_{2} \mathrm{O}(3 \mathrm{mmol})$ prepared in $0.01 \mathrm{M}$ hydrochloric acid was rapidly injected by a plastic tube to $80 \mathrm{~mL} 2 \mathrm{M}$ ammonia solution. The system was stirred under $\mathrm{N}_{2}$ for $1 \mathrm{~h}$ at room temperature. The precipitated was washed with pure ethanol and separated by magnetic decantation. Finally, superparamagnetic nanoparticles were dried under vacuum at $70{ }^{\circ} \mathrm{C}$.

Functionalizing Super paramagnetic Nanoparticles by (3-aminopropyl)triethoxysilane)

A suspension of superparamagnetic nanoparticles was sonicated in $30 \mathrm{~mL}$ ethanol for $30 \mathrm{~min}$ to get uniform dispersion. A solution of $0.7 \mathrm{~mL}$ concentrated ammonia in $9.3 \mathrm{~mL}$ double distilled water was added to nanoparticle suspension. After $15 \mathrm{~min}$ of sonication, a solution of $1.8 \mathrm{mmol}$ APTES and $5 \mathrm{ml}$ ethanol was injected to the sonicator. Sonochemical treatment was aged $2 \mathrm{~h}$ at room temperature. After $1 \mathrm{~h}$ of sonication, a very stable black colored magnetic fluid was obtained. The precipitate was collected with a magnet, and washed with ethanol (three times). Finally, the functionalized super paramagnetic nanoparticle solid was obtained by ethanol evaporation at a reduced pressure chamber.

\section{Results and Discussions}

\section{Superparamagnetic Iron Oxide/SiO ${ }_{2}-\mathrm{NH}_{2}$ Characterization \\ FT-IR study}

The FTIR spectra of $\mathrm{Fe}_{3} \mathrm{O}_{4}$, and super paramagnetic iron oxide $/ \mathrm{SiO}_{2}-\mathrm{NH}_{2}$ nanoparticles were presented in Figure 1. For both nanoparticles, absorption peaks at $581 \mathrm{~cm}^{-1}$ were observed, which corresponded to the $\mathrm{Fe}-\mathrm{O}$ magnetite phase vibration of nanoparticle [13,15]. The observed bands at 1221, 1046, 991 and 993 $\mathrm{cm}^{-1}$ of super paramagnetic iron oxide $/ \mathrm{SiO}_{2}-$ $\mathrm{NH}_{2}$ were related to the deformation vibration and stretching of $\mathrm{SiO}_{2}$ reflecting the coating of silica on the magnetite surface. Successful amino propyl functionalization of the silica layer on super paramagnetic iron oxide $/ \mathrm{SiO}_{2}$ was also evidenced by the absorption at 2808, 1603, and $693 \mathrm{~cm}^{-1}$, attributed to the stretching and bending vibrations of amino groups. The absorption peaks in the region of $2800-3025 \mathrm{~cm}^{-1}$ were 
associated with the stretching vibration of methylene groups of super paramagnetic iron oxide $/ \mathrm{SiO}_{2}-\mathrm{NH}_{2}$. The results verified the formation of a silica shell on the $\mathrm{Fe}_{3} \mathrm{O}_{4}$ surface which was functionalized with amino groups.

\section{X- Ray Diffraction Pattern}

The crystal structure of the nanoparticles was identified with $\mathrm{X}$ - ray diffraction pattern. Diffraction peaks $2 \theta$ at 30.0, 35.6, 43.8, 54.2, 57.2 and 62.5 are shown in Figure 2 indexed to (220) (311) (400) (422) (511) and (440). This showed that the crystal structure of superparamagnetic Iron Nanocrystal was inverse spinel [16]. The particle size of the magnetite was calculated using the Scherer equation as $11.3 \mathrm{~nm}$ [17].

\section{Scanning Electron Microscope}

To determine the average particle size and morphology of super paramagnetic nanoparticles, scanning Electron Microscope (SEM) was used. The SEM images of superparamagnetic nanoparticles showed particles with amorph surface.

\section{BET and Potential of zero charge}

Surface areas of superparamagnetic nanoparticle and superparamagnetic nanoparticle $/ \mathrm{SiO}_{2}-\mathrm{NH}_{2}$ were measured according to BET procedure $[18,19]$. The results showed that surface areas of superparamagnetic nanoparticle and superparamagnetic nanoparticle $/ \mathrm{SiO}_{2}-\mathrm{NH}_{2}$ are 112.3 , and $208.0 \mathrm{~m}^{2} / \mathrm{g}$, respectively.

The $\mathrm{pH}$ of zero charge $\left(\mathrm{pH}_{\mathrm{zcp}}\right)$ of superparamagnetic nanoparticle and superparamagnetic nanoparticle $/ \mathrm{SiO}_{2}-\mathrm{NH}_{2}$ were determined previously in a wide $\mathrm{pH}$ range [13]. It was shown that the $\mathrm{pH}$ of zero charge of superparamagnetic nanoparticle $/ \mathrm{SiO}_{2}-\mathrm{NH}_{2}$ is about 2.8 which is in agreement with the literature [13, 20-24].

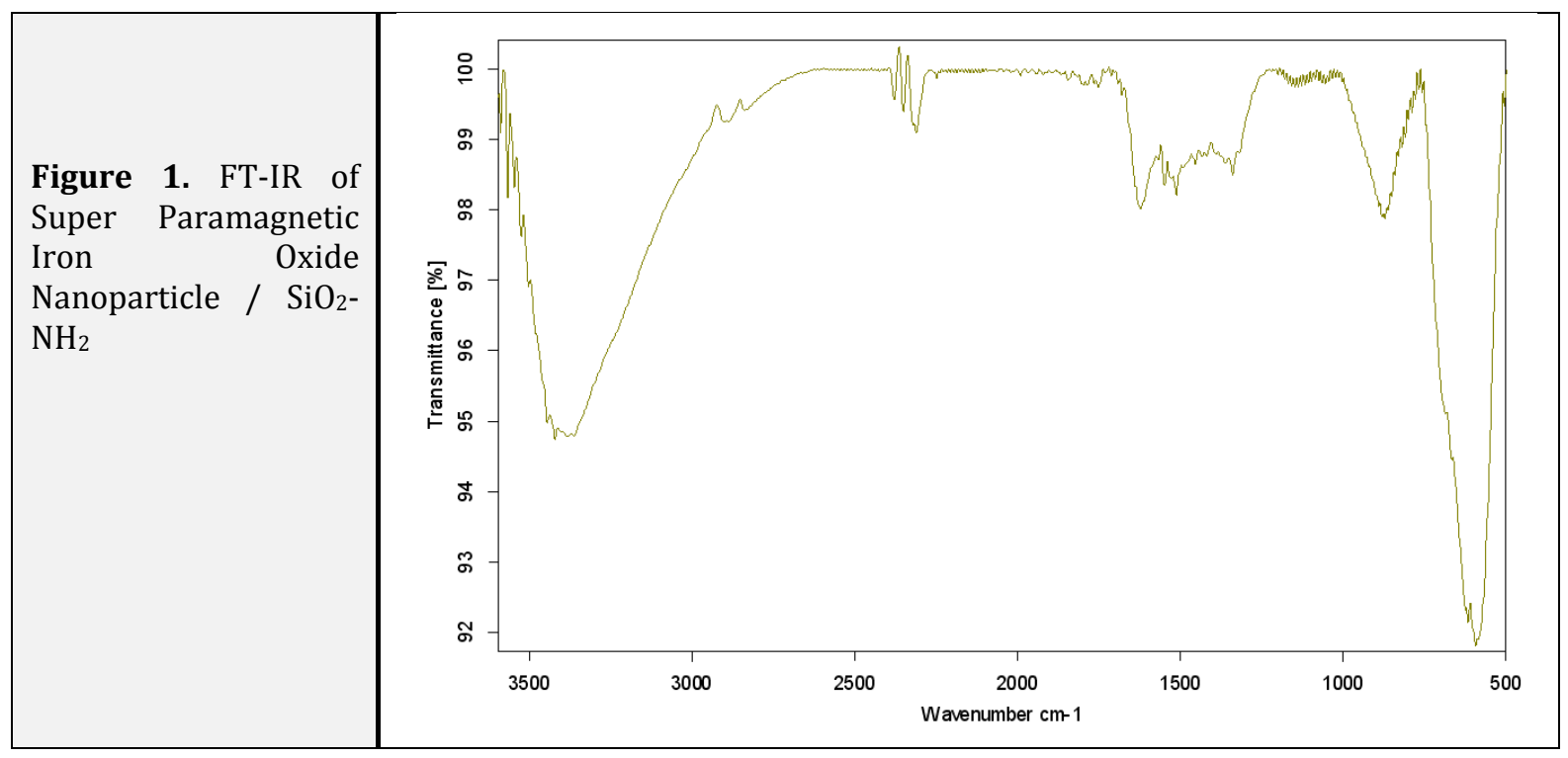




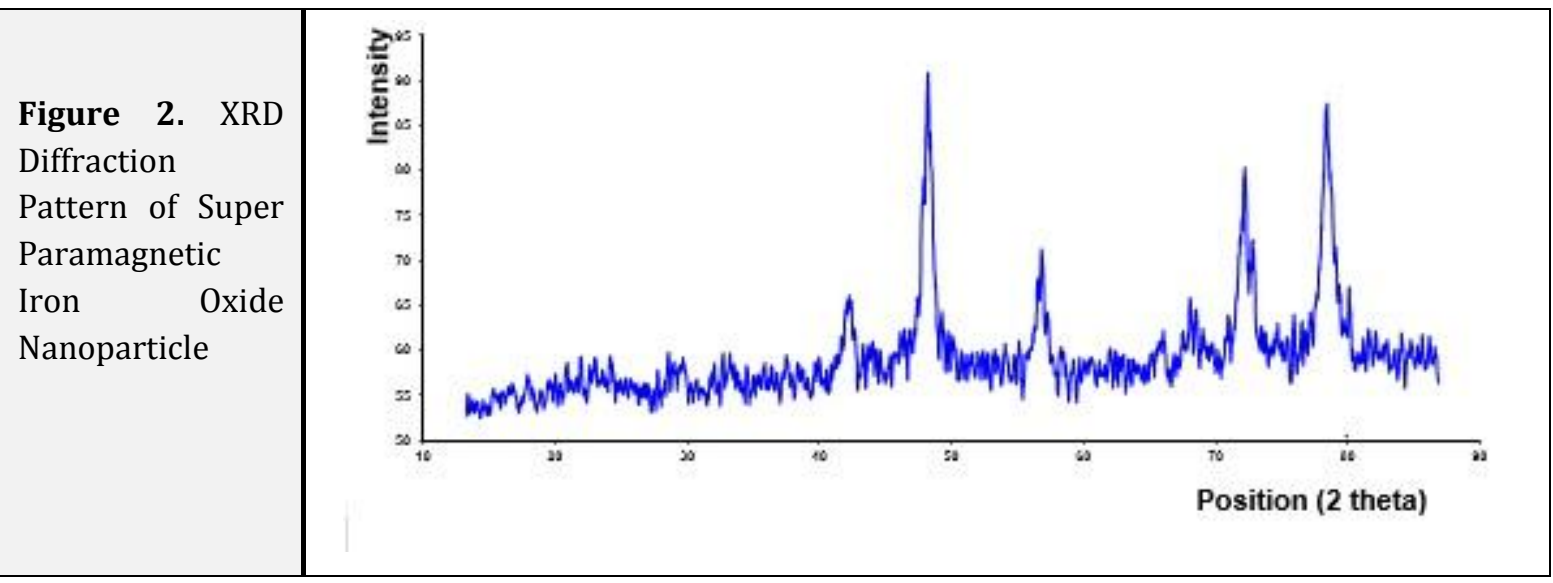

\section{Adsorption Experiments}

Batch experiments were performed to evaluate the equilibrium studies. Briefly, 0.2 $\mathrm{g}$ of superparamagnetic nanoparticle $/ \mathrm{SiO}_{2}-$ $\mathrm{NH}_{2}$ added to $0.4 \mathrm{mmol}$ of arsenic ion. Hydrochloric acid and sodium hydroxide solutions $(0.1 \mathrm{M})$ were used to control the $\mathrm{pH}$. The mixed solution was shaken at room temperature for $15 \mathrm{~min}$. After reaching the adsorption equilibrium, the nanoparticles were magnetically separated and residual arsenic ion concentration was determined. The removal percentage was determined with following expression:

$$
R \%=\frac{C_{0}-C_{e}}{C_{0}} \times 100
$$

where $\mathrm{C}_{0}$ and $\mathrm{C}_{\mathrm{e}}$ were the initial and the final arsenic concentration (mmol/L). All adsorption experiments were performed in triplicate to insure the repeatability of our results.

The optimization of experimental parameters was carried out for As (III) adsorption. The adsorption experiments show the maximum arsenic adsorption at $0.2 \mathrm{~g}$ nanoparticle. The adsorption isotherms of As (III) on the nanoparticle as a function of As (III) concentration $(\mathrm{pH} \mathrm{5}$, room temperature and $15 \mathrm{~min}$ adsorption time) was shown in Figure 3. The adsorption data were fitted with Freundlich isotherm model $[25,26]$.

$$
q_{e}=\frac{q_{m} b C_{e}}{1+b C_{e}}
$$

where $\mathrm{q}_{\mathrm{e}}(\mathrm{mmol} / \mathrm{L})$ and $\mathrm{C}_{\mathrm{e}}(\mathrm{mmol} / \mathrm{L})$ were the adsorbed concentration and total concentration at the equilibrium time. $\mathrm{q}_{\mathrm{m}}$ (mmol/g) was the adsorption capacity, and b ( $\mathrm{L} / \mathrm{mmol})$ was the affinity coefficient.

The maximum adsorption capacity of As (III) on the nanoparticle was obtained as 156 mgg-1. Superparamagnetic iron oxide $/ \mathrm{SiO}_{2}$ $\mathrm{NH}_{2}$ nanoparticle had small size and high surface area of $208.0 \mathrm{~m}^{2} \mathrm{~g}$ than bare iron 
nanoparticles $112.3 \mathrm{~m}^{2} \mathrm{~g}$. The decreased size and enhanced surface area of Iron Oxide nanoparticles enhanced the adsorption sites for arsenic and increased the adsorption capacity. Concentration of nanoparticle and dispersion time was important parameters in the adsorption process. The results of nanoparticle concentration on the adsorption showed that the adsorption percentage of arsenic increases with increases of nanoparticle concentration.

The effect of contact time on the adsorption capacity of As (III) on super paramagnetic iron oxide $/ \mathrm{SiO}_{2}-\mathrm{NH}_{2}$ nanoparticle was studied. The adsorption kinetics data showed pseudo-second order kinetics.

Figure 4 shows the effect of initial solution $\mathrm{pH}$ on the removal of As (III). The maximum removal occurred at $\mathrm{pH} 5$ and then the removal capacity remained constant. The high removal efficiency at low $\mathrm{pH}$ can be attributed to the fact that the surface of the adsorbent becomes highly protonated and positively charged, which favored the uptake of As (III) through electrostatic attraction.

The adsorption of As (III) ions increased with increase of temperature from 15 to $45{ }^{\circ} \mathrm{C}$. The enhancement of adsorption capacity with temperature may be due to the enlargement of pore size and/ or activation of adsorbent surface as observed by Namasivayam et al. [27]. The effect of ionic strength was studied in the presence of $\mathrm{Na} \mathrm{Cl}$ and shows negligible change in arsenic adsorption on As (III).
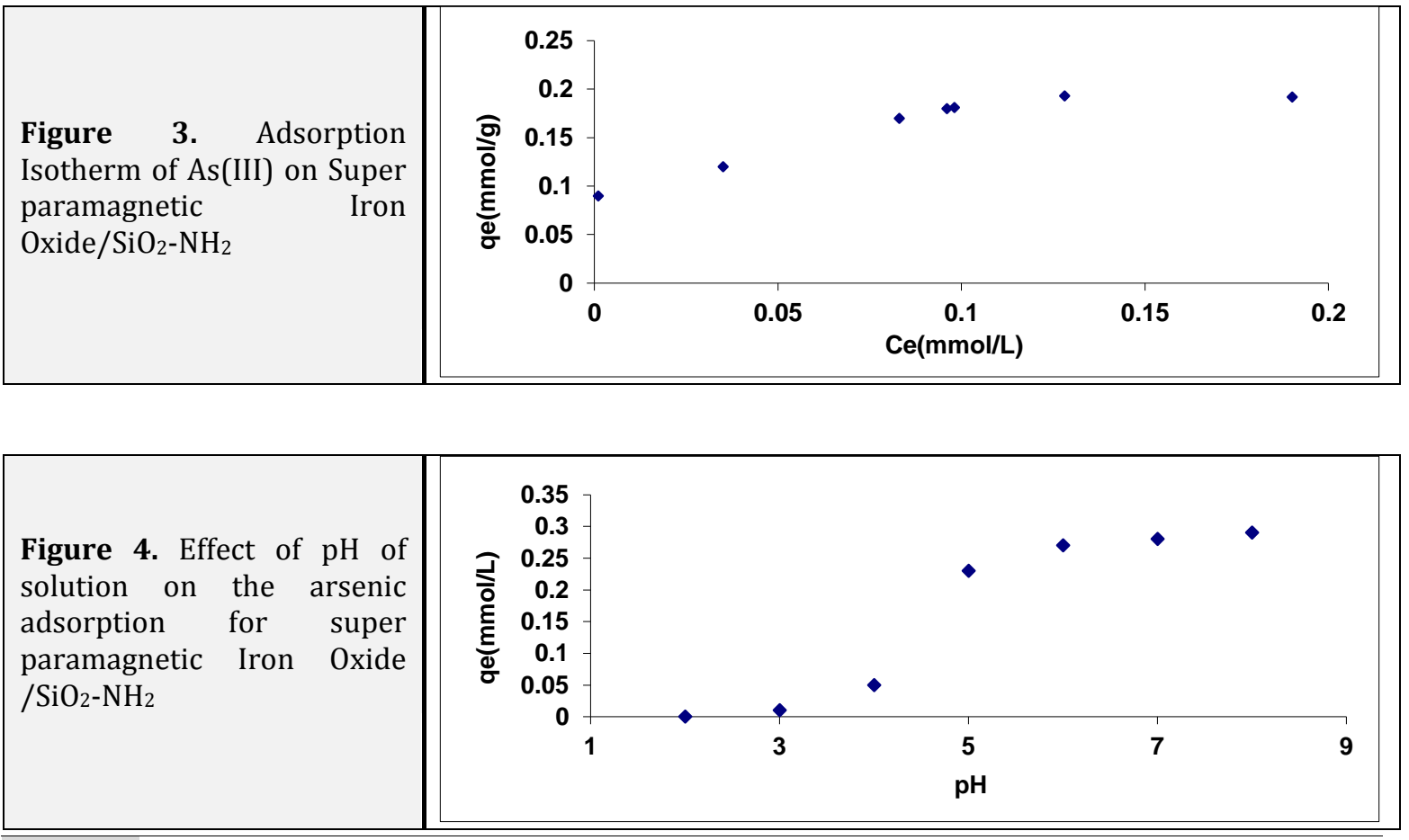


\section{Conclusion}

The existence of trace toxic heavy metals such as arsenic in water and groundwater is an important issue. Here a novel superparamagnetic iron oxide $/ \mathrm{SiO}_{2}-\mathrm{NH}_{2}$ was synthesized via facile, fast, and low-cost process and further was used as a highly efficient adsorbent for As (III) from aqueous solution. $\mathrm{SiO}_{2}$ reduces the serious stacking of superparamagnetic iron oxide and prevents the agglomeration of nanoparticles, and also produced a high tunable surface area, which enabled to high binding capability and excellent adsorption properties for As (III). This adsorbent was stable, low-cost, and environmentally friendly and showed potential application for As (III) removal.

\section{ORCID}

Abbas Farmany (iD): 0000-0002-9671-1696

Hadi Noorizadeh (D): 0000-0001-6894-3150

\section{References}

[1]. E. Terlecka, Environ. Monit. Assess., 2005, 107, 259-284.

[2]. C.J. Moretti, K.P. Henke, C.A. Wentz, Particul. Sci. Technol., 1988, 6, 393-404.

[3]. B. An, Q. Liang, D. Zhao, Water Res., 2011, 45, 1961-1972.

[4]. B.K. Mandal, K.T. Suzuki, Talanta, 2002, 58, 201-235.

[5]. A.B. Shams, S. Tiantian, H. Yunjun, X. Jiang, X. Xinhua, CLEAN - Soil, Air, Water, 2015, 43, 13-26.

[6]. N. Badr, K.M. Al-Qahtani, Environ. Monit.
Assess., 2013, 185, 9669-9681.

[7]. W. Yang, T. Kan, W. Chen, M.B. Tomson, Water Res., 2010, 44, 5693-5701.

[8]. C.T. Yavuz, J.T. Mayo, C. Suchecki, J. Wang, A.Z. Ellsworth, H. Dcouto, E. Quevedo, A. Prakash, L. Gonzalez, C. Nguyen,C. Kelty, V.L. Colvin, Environ. Geochem. Health., 2010, 32, 327-334.

[9]. Y. Jeong, M. Fan, S. Singh, C.L. Chuang, B. Saha, J. Hans van Leeuwen, Chem. Eng. Proces., 2007, 46, 1030-1039.

[10]. J. Wang, S. Zheng, Y. Shao, J. Liu, Z. Xu, D. Zhu, D. J. Colloid Interface Sci., 2010, 349, 293-297.

[11]. Y.F. Huang, Y.F. Wang, X.P. Yan, Environ. Sci. Technol., 2010, 44, 7908-7912.

[12]. V. Chandra, J. Park, Y.Y. Chun, J.W. Lee, I.C. Hwang, K.S. Kim, ACS Nano, 2010, 4, 3979-3986.

[13]. A. Farmany, M. M. Shirmohammadi, S. Kazemi, M. Hatami, S. S. Mortazavi. Desalin. Water Treat., 2016, 9, 57, 27355-27362.

[14]. A.M. Ahmed, A.E. Ali, A.H. Ghazy, Adv. J. Chem. A, 2019, 2, 79-93.

[15]. M. Yamaura, R.L. Camilo, L.C. Sampaio, M.A. Macedo, M. Nakamura, H.E. Toma, J. Magnet. Magnet. Mater., 2004, 279, 210-216. [16]. T.Z. Yang, C.M. Shen, Z.A. Li, H.R. Zhang, C.W. Xiao, S.T. Chen, Z.C. Xu, D.X. Shi, J.Q. Li, H.J. Gao, J. Phys. Chem. B, 2005, 109, 2323323236.

[17]. B.D. Cullity, Elements of X-ray Diffraction, Reading Mass: Addison-Wesley, 
1967.

[18]. S. Brunauer, P.H. Emmett, E. Teller. J. Am. Chem. Soc., 1938, 60, 309-319.

[19]. K.S. Walton, R.Q. Snurr. J. Am. Chem. Soc., 2007, 129, 8552-8556.

[20]. M. Ahmaruzzaman, S., L. Gayatri, Chem.

Eng. J., 2010, 158, 173-180.

[21]. S.S. Mortazavi, A. Farmany, J. Water

Supply: Res. Technol. AQUA, 2016, 65, 37-42.

[22]. A. Farmany, S. S. Mortazavi, H. Mahdavi,

J. Magnet. Magnet. Mater., 2016, 416, 75-80.

[23]. A. Penkova, J.M. Martínez Blanes, S.A.
Cruz, M.A. Centeno, K. Hadjiivanov, J.A. Odriozola, Micro. Mesop. Mater., 2009, 117, 530-534.

[24]. M. Rosenholm, M. Lindén, J. Control. Releas., 2008, 128, 57-164.

[25]. H. Freundlich, H.S. Hatfield, Colloid and Capillary Chemistry, Methuen And Co. LTd; London, 1926, p. 993.

[26]. H. Freundlich, Z. Phy. Chem., 1907, 57, 385-470.

[27]. C. Namasivayam, R.T. Yamuna, Chemosphere, 1995, 30, 561-578.

How to cite this manuscript: Hadi Noorizadeh, Abbas Farmany*, Adsorptive Removal of Arsenic from Aqueous Solutions Using Amino Functionalized Super paramagnetic Iron Oxide Nanoparticle/ $\mathrm{SiO}_{2}, A d v$. J. Chem. $A$, 2019, 2(2), 128-135. 